\title{
Synergistic Effects of Metformin and Cocoa Flavanol on Inflammatory and Oxidant Markers Induced by Carrageenan: Pathophysiological Approach
}

Hani M Abdelsalam*

Hani M Abdelsalam*

Department of Zoology, Faculty of Science, Zagazig University, EGYPT.

\section{Correspondence}

\section{Hani M Abdelsalam}

Department of Zoology, Faculty of Science, Zagazig University, EGYPT.

Email: hmmsama@hotmail.com

History

- Submission Date: 15-06-2019;

- Review completed: 19-07-2019;

- Accepted Date: 10-08-2019.

DOI : 10.5530/ijcep.2019.6.3.26

\section{Copyright}

(C) 2019 Phcog.Net. This is an openaccess article distributed under the terms of the Creative Commons Attribution 4.0 International license.

\begin{abstract}
Background and Aim: The present study aims to evaluate the effects of metformin, cocoa flavanol and their combination as anti-inflammatory and antioxidant drugs. Methods: Forty adult male albino mice are divided into five groups: Control, Carrageenan $(\mathrm{Cg}), \mathrm{Cg}$ Metformin (Met), Cg Cocoa and $\mathrm{Cg}$ Met Cocoa groups. Cg is used to induce the inflammation through injection of it in the paw of the hind leg and into the trunk of mice. Also, Met is applied intraperitoneally at the same time of $\mathrm{Cg}$ injection while Cocoa is received orally seven days before carrageenan injection. Biochemical estimation of inflammatory mediators (COX-2, PGE2, TNF- $\alpha$, CRP) and selected oxidative stress markers (MDA, SOD, GSH) was performed. Results: This study elucidated the marvellous leverage of the metformin, cocoa flavanol and their combination as anti-inflammatory and antioxidant drugs, where metformin and Cocoa decreased all inflammatory mediators (COX-2, PGE2, TNF- $\alpha$, CRP) with high significant $(P<0.01)$ in comparing with $\mathrm{Cg}$ group. In addition, the level of MDA is decreased significantly $(P<0.01)$, while the levels of SOD and GSH are increased significantly $(P<0.01)$ in comparing with $\mathrm{Cg}$ group. Interestingly, their combination restored normal levels of the inflammatory mediators and the oxidative stress markers. Conclusion: I concluded that Met and cocoa are powerful anti-inflammatory substances and can ameliorate the oxidative stress that results from inflammation. Additionally, the mixture of them can retrieve the normal levels of all measured parameters.

Key words: Cyclooxygenase, Prostaglandin, Metformin, Carrageenan, Cocoa, Inflammation, Reactive oxygen species.
\end{abstract}

\section{INTRODUCTION}

The biguanide metformin is antidiabetic type 2 drug. ${ }^{[1]}$ Influences of metformin on the formation of the glucose from the non-carbohydrate source are accredited to activation AMP-Activated Protein Kinase (AMPK). ${ }^{[2]}$ Metformin-induced AMPK act ivation has caused suppression of acetyl-CoA carboxylase, leading to a lessening in hepatic lipid gathering and rebuilding of insulin sensitivity. ${ }^{[3]}$ Moreover, the activity of Hormone-Sensitive Lipase (HSL) that is controlled by reversible phosphorylation of serine residues has been stated as repressed by AMPK activation. ${ }^{[4]}$

Herbal polyphenols have long been considered as antioxidants. ${ }^{[5]}$ Flavanols present in the blood and vascular structures may rise vascular NO concentration by interfering with reactions between $\mathrm{NO}$ and superoxides. Cocoa flavanols and procyanidins have straight special effects on the expression and activity of Endothelial Nitric Oxide Synthase (eNOS) and have powerful antioxidant properties. ${ }^{[5]}$ The term "cocoa" refers to the cocoa powder which is the outcome of crushing cocoa seeds and the removal of cocoa butter

Cite this article: Abdelsalam HM. Synergistic Effects of Metformin and Cocoa Flavanol on Inflammatory and Oxidant Markers Induced by Carrageenan: Pathophysiological Approach. Int J Clin Exp Physiol. 2019;6(3):95-9 
standard laboratory food and had free access to food and water. All mice received humane care in compliance with the Ethical Committee of Zagazig University and in accordance with the National Institutes of Health (NIH) Guidelines for the Care and Use of Laboratory Animals. I authorize that the experimental protocol was approved by the Zoology Department, Faculty of Science, Zagazig University.

\section{Experimental Design: The animals were assigned to five groups as follows}

Group I (control group): Eight mice that received no treatment for 2 months.

Group II (Carrageenan group) (Cg. Group): Eight mice injected with $200 \mu \mathrm{l}$ of $1 \%$ solution of carrageenan in saline into the left hind paw and into trunk region subcutaneously under light ether anaesthesia. ${ }^{[8]}$ After 15 min observing the swelling in left hind paw at the inflammation site.

Group III (Carrageenan+Metformin group) (Cg. Met. Group): Eight mice injected with $200 \mu \mathrm{l}$ of $1 \%$ solution of carrageenan in saline into the left hind paw and into trunk region subcutaneously under light ether anaesthesia ${ }^{[8]}$ then metformin is dissolved/diluted in isotonic saline and applied Intraperitoneally (I.P.) in a volume of $2 \mathrm{~mL} / \mathrm{kg}$ body weight, me tformin was administered at the same time as carrageenan. ${ }^{[9]}$

Group IV (Carrageenan+CoCoa group) (Cg. Coca. Group): Eight mice injected with $200 \mu \mathrm{l}$ of $1 \%$ solution of carrageenan in saline into the left hind paw and into trunk region subcutaneously under light ether anaesthesia ${ }^{[8]}$ Also, received Cocoa orally 7 days before carrageenan injection (4.6 g flavanols/Kg.b.w.) ${ }^{[10]}$

Group V (Carrageenan+Metformin+ CoCoa group) (Cg. Met. Coca group): Eight mice injected with $200 \mu \mathrm{l}$ of $1 \%$ solution of carrageenan in saline into the left hind paw and into trunk region subcutaneously under light ether anaesthesia ${ }^{[8]}$ then metformin is dissolved/diluted in isotonic saline and applied intraperitoneally (I.P.) in a volume of $2 \mathrm{~mL} / \mathrm{kg}$ body weight, metformin was administered at the same time as carrageenan. ${ }^{[9]}$ Also, received 5\% Cocoa orally 7 days before carrageenan injection (4.6 g flavanols/Kg.b.w.). ${ }^{[10]}$

At the end of the experiment, blood samples were collected ${ }^{[11]}$ and then mice in all groups were sacrificed after $6 \mathrm{hr}$ of carrageenan injection ${ }^{[12]}$ via intraperitoneal injection of $25 \mathrm{mg} / \mathrm{kg}$ sodium thiopental. ${ }^{[13]}$ The time points when the drugs were administered were chosen according to the data about the time course of carrageenan-induced hyperalgesia and the time course of antihyperalgesic effects produced by the examined drugs. ${ }^{[14]}$

COX activity assay: COX activity was measured by using an enzyme immune assay kit (Cayman cat no.760151). The kit measures the peroxidase activity of cyclooxygenase. The peroxidase activity was measured colorimetrically by monitoring the appearance of oxidized N, N, N', N' tetramethyl-p-phenylenediamine (TMPD). According to manufacturer's instructions, animals were perfused with Tris- $\mathrm{HCl}$, testis were removed and homogenized in cold Tris- $\mathrm{HCl}$ buffer followed by centrifuging at $10,000 \mathrm{~g}$ for $15 \mathrm{~min}$ at $4^{\circ} \mathrm{C}$ and the supernatant stored at $8^{\circ} \mathrm{C}$ until assayed. The samples were assayed in triplicate and each sample was assayed for COX-2 activity using isospecific inhibitors supplied with the kit. ${ }^{[15]}$

Prostaglandin levels assay: Total PGs in the tissue samples were quantified using an enzyme immuno assay kit (Cayman kit cat no.514012). This assay is acetylcholinesterase (Nardi et al.) Competitive enzyme assay. The PG-AChE conjugate (PG tracer) competes with the PG in the sample in binding to the PG anti-serum, which in turn binds to the antibody in the well. The number of PG tracers bound to the well is inversely proportional to the amount of free PG present in the well during incubation. ${ }^{[15]}$

Determination of TNF- $\alpha$ : Levels were estimated in the rat's plasma using rat specific TNF- $\alpha$ sandwich ELISA (IBL International $\mathrm{GmbH}$,
Hamburg, Germany) according to the manufacturer's protocol. Briefly, a 96-microwell plate coated with a polyclonal antibody to rat TNF-a was used. All of the wells were washed four times with washing buffer; finally, $100 \mu \mathrm{L}$ of TMB substrate solution was added to all of the wells and the plate was incubated in the dark for $10 \mathrm{~min}$ at room temperature. The enzyme reaction was stopped quickly by pipetting $100 \mu \mathrm{L}$ of stop solution into each well and the plate was read immediately using a micro plate reader (VersaMax-Tunable Micro plate, Reader, USA) at $450 \mathrm{~nm}$.

Determination of CRP: Plasma CRP measured according to the procedures described in IMMULITE CRP assay kit (Diagnostic Product Corporation (DPC) Los Angeles, CA). The sensitivity of the CRP assay kit-defined as the concentration two standard deviations above the response at zero dose-was $\approx 1 \mathrm{pg} / \mathrm{mL}$.

Lipid peroxidation estimation (as reflected in amounts of measurable MDA): Lipid peroxidation was estimated by measuring the level of thiobarbituric acid reactive substances (TBARS) in tissues by the method of Niehaus Jr and Samuelsson, 1968. ${ }^{[16]}$ Briefly, The tritiated acid was treated with diazomethane, diluted with methyl arachidonate and purified by chromatography on a column of silicic acid impregnated with AgNO. The product was radio chemically pure as judged by thin-layer chromatography and gas-liquid chromatography and had a specific activity of 5 x 109 disintegrations/min/micromole.

SOD estimation: Superoxide dismutase was assayed using the method of Lima et al. 2006. ${ }^{[17]}$ Briefly, The assay mixture in a total volume of $1 \mathrm{~mL}$ consisted of $0.1 \mathrm{~mol} / \mathrm{L}$ sodium phosphate buffer $(\mathrm{pH} 7.8)$ and $0.08 \mathrm{mmol} / \mathrm{L}$ EDTA at a 1:1 proportion. The $0.1 \mathrm{~mL}$ of the tissue sample (1:1000) after dilution was added to $2.3 \mathrm{~mL}$ of distilled water, after which $1 \mathrm{~mL}$ of assay mixture with EDTA and sodium phosphate buffer. The increase in absorbance due to oxidation of quercetin at 0 and $20 \mathrm{~min}$ was measured spectrophotometrically at $406 \mathrm{~nm}$. In the blank, a tissue sample was substituted by equal quantities of distilled water. One unit of SOD activity is defined as the quantity of the enzyme that inhibited quercetin oxidation by $50 \%$ under given experimental conditions.

GSH estimation: GSH concentrations were determined by the method of Niehaus Jr and Samuelsson, 1968. ${ }^{[16]}$ Briefly, Reduced Glutathione (GSH) was measured by reaction with 5,5'-dithiobis(2- nitrobenzoic acid) (DTNB) to give a compound that absorbs at $412 \mathrm{~nm}$ (Ellman's method). Reduced glutathione in the supernatant fractions was also assayed enzymatically using glutathione S-transferase and an excess of the other substrate.

\section{RESULTS}

\section{Biochemical Estimation of COX-2, PGE ${ }_{2}$ TNF-a and CRP}

In carrageenan group, the mean of all inflammatory markers (COX-2, $\mathrm{PGE}_{2}$, TNF- $\alpha$ and CRP) increased with high significant value $(P<0.001)$ in comparison with the means of these markers in the control group. In $\mathrm{Cg}$ Met, $\mathrm{Cg}$ Cocoa and $\mathrm{Cg}$ Met Cocoa groups, all levels of COX-2, $\mathrm{PGE}_{2}$, TNF- $\alpha$ and $\mathrm{CRP}$ decreased with high significant value $(P<0.001)$ in comparison with $\mathrm{Cg}$ group (Table 1).

\section{Biochemical Estimation of MDA, SOD and GSH in the liver}

As shown in Table 2, Cg group exhibited a statistically high significant $(P<0.001)$ in the level of MDA with the elevation of its mean as compared with the control group while the levels of SOD and GSH are reduced in comparing with the same group. In $\mathrm{Cg}$ Met, $\mathrm{Cg}$ Cocoa and Cg Met Cocoa groups, all levels of MDA decreased with high significant value $(P<0.001)$ in comparison with $\mathrm{Cg}$ group while the mean of SOD and GSH are elevated with high significant value $(P<0.001)$ in comparison 
Table 1: Levels of COX-2, PGE 2 , TNF- $a$ and CRP in various study groups.

\begin{tabular}{|c|c|c|c|c|c|}
\hline & Control & Carrageenan & $\begin{array}{l}\text { Carrageenan Metformin } \\
\text { (Cg Met) }\end{array}$ & $\begin{array}{l}\text { Carrageenan Cocoa } \\
\text { (Cg Cocoa) }\end{array}$ & $\begin{array}{c}\text { Carrageenan Metformin+Cocoa } \\
\text { (Cg Met Cocoa) }\end{array}$ \\
\hline $\operatorname{COX}-2(\mathrm{ng} / \mathrm{mL})$ & $71.94 \pm 0.89$ & $95.34 \pm 1.07^{\mathrm{a}}$ & $81.64 \pm 1.1^{\mathrm{b}}$ & $87.38 \pm 0.61^{\mathrm{b}}$ & $74.70 \pm 1.06^{\mathrm{b}}$ \\
\hline PGE2 (pg/mL) & $44.44 \pm 0.99$ & $220.66 \pm 2.16^{\mathrm{a}}$ & $104.61 \pm 3.21^{\mathrm{b}}$ & $144.55 \pm 3.43^{\mathrm{b}}$ & $69.71 \pm 3.59^{b}$ \\
\hline Sign. $\mathrm{P}<$ & & $0.001^{\star *}$ & $0.001^{\star \star}$ & $0.001^{* *}$ & $0.001^{* *}$ \\
\hline CRP (mg/dl) & $0.25 \pm 0.02$ & $0.63 \pm 0.03^{\mathrm{a}}$ & $0.36 \pm 0.019^{b}$ & $0.37 \pm 0.026^{\mathrm{b}}$ & $0.21 \pm 0.039^{b}$ \\
\hline Sign. $\mathrm{P}<$ & & $0.001^{* *}$ & $0.001^{* *}$ & $0.001^{* *}$ & $0.001^{* *}$ \\
\hline
\end{tabular}

a: Negative highly Significant between control and Carrageenan, b: Positive highly Significant both Carrageenan and other parameters, ${ }^{* *}$ Highly Significant

Table 2: Levels of MDA, SOD and GSH in the liver of various study groups.

$\begin{array}{cccccc} & \text { Control } & \text { Carrageenan } & \begin{array}{c}\text { Carrageenan } \\ \text { Metformin (Cg Met) }\end{array} & \begin{array}{c}\text { Carrageenan Cocoa } \\ \text { (Cg Cocoa) }\end{array} & \begin{array}{c}\text { Carrageenan Metformin+Cocoa (Cg } \\ \text { Met Cocoa) }\end{array} \\ \text { MDA (nmol/ mg of protein } & 0.17 \pm 0.01 & 0.83 \pm 0.026^{\mathrm{a}} & 0.28 \pm 0.008^{\mathrm{b}} & 0.39 \pm 0.018^{\mathrm{b}} & 0.20 \pm 0.007^{\mathrm{b}} \\ \text { Sign. P }< & & 0.001^{* *} & 0.001^{* *} & 0.001^{* *} & 0.001^{* *} \\ \text { SOD (U/mg of protein) } & 4.18 \pm 0.143 & 1.61 \pm 0.125^{\mathrm{a}} & 3.41 \pm 0.128^{\mathrm{b}} & 2.44 \pm 0.128^{\mathrm{b}} & 4.02 \pm 0.059^{\mathrm{b}} \\ \text { Sign. P }< & & 0.001^{* *} & 0.001^{* *} & 0.001^{* *} & 0.001^{* *} \\ \text { GSH (nmol/ mg of protein) } & 0.53 \pm 0.011 & 0.16 \pm 0.045^{\mathrm{c}} & 0.44 \pm 0.025^{\mathrm{d}} & 0.32 \pm 0.025^{\mathrm{d}} & 0.57 \pm 0.0 .017^{\mathrm{d}} \\ \text { Sign. P }< & & 0.001^{* *} & 0.001^{* *} & 0.001^{* *} & 0.001^{* *}\end{array}$

a: Negative highly Significant between control and Carrageenan, b: Positive highly Significant both Carrageenan and other parameters, c: Positive highly Significant between control and Carrageenan, d:Negative highly Significant both Carrageenan and other parameters, ${ }^{*}$ Highly Significant.

with Cg group. In Cg Met Cocoa group all levels of MDA, SOD and GSH become slightly near to the normal levels of the control group.

\section{DISCUSSION}

Various types of inflammation are induced by Carrageenan such as paw oedema and acute monoarthritis experimentally. In rodents, it induces inflammation, which has widely been approved as a suitable model for examining the efficiency of anti-inflammatory and/or analgesic drugs. ${ }^{[18]}$ WBCs count and platelets are increased at the site of inflammation after carrageenan injection due to the discharge of inflammatory cytokines, which elevates the recruitment of neutrophil counts. ${ }^{[19]}$ COX-2 regulates the production of the modifiable arachidonic acid pathway in inflammatory cells for curing and restoring. Therefore, stopping the releasing of COX and inhibiting the production of prostaglandins, is a vital way to prevent inflammatory response. ${ }^{[8]} \mathrm{Guay}$, et al. found that the stimulation of COX-2 that occurs in the central nervous system during carrageenaninduced paw inflammation leads to an elevation in PGs, prostacyclin and TX in the early phase and to a large increase in PGE2 production linked to selective up-regulation of mPGES-1. ${ }^{[20]}$

Our results showed that injection of $\mathrm{Cg}$ caused elevation of the mean of all inflammatory markers as COX-2, PGE $_{2}$ with high significant value (0.001) in comparison with the means of these markers in the control group. This comes in the same line of Nantel et al. who statd that $\mathrm{Cg}$ intraplantar injection prompts a significant rise of COX-2 expression, as well as prostaglandin E2 manufacture. ${ }^{[21]}$ Where induction of inflammation in paw by carrageenan is biphasic: the first phase occurs within $1 \mathrm{hr}$ of carrageenan inflammation and is associated with the release of the neurotransmitters as histamine and serotonin. The second phase (over $1 \mathrm{hr}$ ) is triggered by an amplified production of prostaglandins in the inflammatory zone and the two phases are mediated by kinins. ${ }^{[22]}$ In the prostaglandin $\left(\mathrm{PGE}_{2}\right)$ biosynthesis pathway, $(\mathrm{COX}-2)$ is the main enzyme that stimulates the conversion of arachidonic acid to $\mathrm{PGE}_{2} \cdot{ }^{[23]}$ Chopade, et al. explained that Cg elevates COX-2 and $\mathrm{PGE}_{2}$ levels due to a positive feedback mechanism that, controls COX-2 expression in case of chronic inflammatory muscle hyperalgesia. ${ }^{[24]}$

In the present study, Cg group appeared a significant increase in the level of TNF- $\alpha$ and CRP after the induction of inflammation by Cg. These results are agreed with Ogata, et al. who demonstrated that $\mathrm{Cg}$ induced WBCs to release TNF-alpha due to carrageenan appears to increase TNF-a mRNA in WBCs. ${ }^{[25]}$ Interestingly, Vazquez et al. demonstrated that Cg-induced paw edema has systemic consequences characterized by the augmented level of acute-phase proteins and lung inflammatory responses including lung edema, fibrin deposition and leukocyte infiltration. ${ }^{[26]}$

These results are interpreted where, inflammatory reactions, infections, or tissue injury stimulate acute phase proteins synthesis, such as CRP. It is manufactured primarily in the liver, but it may also be created by local inflammatory cells in the range of tissue damage. ${ }^{[27]}$ Vazquez et al. determined the CRP levels after carrageenan injection and found that its levels elevated at $2 \mathrm{hr}$, peaked at $8 \mathrm{~h}$ and did not return to baseline even at $48 \mathrm{hr}^{[27]}$ Most inflammatory biomarkers such as fibrinogen and CRP elevated significantly after the inflammation response. ${ }^{[28]}$

Our biochemical results proved that metformin act as an anti-inflammatory drug where administration of metformin, greatly reduced the levels of all inflammatory mediators (COX-2, PGE2, TNF- $\alpha$ and CRP). These consequences are explained by Z.-s. Wang et al. who speculated that metformin reduced the activation of macrophages subsequent to ischemia and repressed the expression of COX-2 and Caspase- 3 and, thereby, diminished the inflammatory responses and apoptosis of the epithelial cell of the renal tubule. ${ }^{[29]}$ Also, Liu et al. found that metformin treatment can reduce synthesis of COX2 and PGE2 and suppress the functions of macrophages, such as LPS induced synthesis of IL- 6 and TNF- $\alpha^{[30]}$ They also, found that metformin uses its anticancer effects by inhibiting COX2/ $\mathrm{PGE}_{2}$ 
axis. These results were in accordance with Kim, et al. who also suggested that metformin might control COX2 via stimulating AMP-activated protein kinase (AMPK) evidenced by that compound $\mathrm{C}$, a specific AMPK inhibitor and AMPK siRNA could release metformin-mediated COX-2 expression. ${ }^{[31]}$ The inhibitory effect of Metformin on COX2 is occurred by inhibiting inflammatory mediators NF- $\mathrm{kB}$ and STAT3. ${ }^{[32]}$

Andújar, et al. demonstrated the anti-inflammatory effects of a cocoa extract experimentally where, it decreased neutrophil infiltration, NO production, COX-2 expression. ${ }^{[33]}$ The suppression of these transcription factors falls the production of COX-2, IL6, IL-1 $\beta$ and TNF- $\alpha$. In the present study, the results revealed that Cocoa administration caused a significant decreasing in the levels of COX2, PGE2, TNF- $\alpha$ and CRP. Our results come in agreement with Martín, et al. who explained that antiinflammatory properties of cocoa polyphenols may also indirectly result from their extraordinary antioxidant capacity ${ }^{[34]}$ Also, Antioxidant activity is done by the capability to scavenge free oxygen and nitrogen species, abrogating the pro-inflammatory activity of ROS-generating enzymes such as COX, LOX and iNOS. Administration for 7 days of a high-cocoa diet $(4.8 \mathrm{~g} / \mathrm{kg} /$ day $)$ decreased the creation of the pro-inflammatory cytokines IL- 6 and TNF- $\alpha$, as well as of NO and ROS, in rat peritoneal macrophages ex vivo. ${ }^{[35]}$ Also, it is reported that Cocoa Phenolic Extract (CPE) markedly diminished the inflammatory markers by obstruction of the pathways of TNF- $\alpha$-NO, COX-II-PGE2 and 5-LOX-LT. The main inducer to inflammation is ROS and it has been noted that the capability of macrophages to yield ROS depends on the level of tissue damage. CPE has inhibitory activity on the production of PGE2 and flavonoids have an oppressive effect on the production of PGE2 and LT. ${ }^{[36]}$ Also, our results are consistent with Parsaeyan, et al. who revealed that serum level of TNF- $\alpha$, IL- 6 and hs-CRP lessened significantly in patients under Cocoa powder regimen. ${ }^{[37]}$ The relation between malondialdehyde and inflammatory markers (hs-CRP, IL-6, TNF- $\alpha$ ) indicated that a significant positive correlation exists between them. Our investigations showed that the combination of metformin with cocoa caused a tremendous depression of the levels of the inflammatory mediators and slightly returned them to the normal levels as compared to the control group.

Local inflammation that induced by Carrageenan was reported to be associated with the production of ROS and to play a vital role in the creation of oxidative stress. ${ }^{[38]}$ In this study, biochemical investigations clarified that $\mathrm{Cg}$ treatment caused increasing with high significant $(0.001)$ in the level of MDA with as compared with the control group while the levels of SOD and GSH are decreased in comparing with the same group. In Cg Met, Cg Cocoa and Cg Met Cocoa groups, all levels of MDA decreased with high significant value (0.001) in comparison with Cg group while the mean of SOD and GSH are elevated with high significant value (0.001) in comparison with Cg group. In Cg Met Cocoa group all levels of MDA, SOD and GSH become slightly near to the normal levels of the control group. Earlier research has reported that ROS overproduction may lead to increased lipid peroxidation, ${ }^{[39]}$ hence the MDA level, a biomarker involved in lipid peroxidation. ${ }^{[28]}$ Nardi et al. reported that in acute and chronic inflammation, the manufacture of $\mathrm{O}_{2}$ is amplified at a rate that overwhelms the capacity of the endogenous SOD enzyme defence system to eliminate it. ${ }^{[40]}$

The alteration of the levels of MDA, SOD and GSH was explained where metformin decreases levels of ROS and NO in the mouse adipose-derived stem cells and augmented the antioxidant system, such as SOD. ${ }^{[4]}$ Metformin can inhibit the oxidative stress associated with arsenic and butyric acid by reducing the level of ROS and MDA and increasing the production and activity of GSH. ${ }^{[42]}$ Cho et al. revealed that administration of metformin stops the production of free oxygen radicals by direct obstructing of the complex I electron transfer complex chain. ${ }^{[43]}$ Metformin can reduce ROS production, inhibit NADPH oxidase (NOX) activation and exacerbate antioxidant activity and SOD expression in mesothelial cells. ${ }^{[44]}$ Metformin cleans the ROS from brain tissue By prompting the production and increasing the activity of the antioxidant system, such as SOD. ${ }^{[45]}$

Our results are in the same line with Decroix, et al. who demonstrated a $12 \%$ decrease in MDA after 14 days of CF intake compared to baseline. ${ }^{[46]}$ In addition, $\mathrm{CF}$ protects against oxidative stress and inflammation. ${ }^{[46]} \mathrm{CF}$ can reduce Reactive Oxygen Species (ROS) formation (e.g. superoxide) and repress the formation of peroxynitrite because of their antioxidant capacities. ${ }^{[46]}$ Also Taub et al. stated that 3 months of CF intake leads to an increased ratio of reduced vs. oxidized gluthathione (GSH:GSSG). ${ }^{[47]}$ These resluts are explained by other reports Steffen, et al. ${ }^{[48]}$ which stated that $\mathrm{CF}$, act not only as a direct scavenger to deactivate ROS, ${ }^{[49]}$ but also promote the expression and activity of endogenous antioxidants, such as SOD, GSH, catalase and GPX. ${ }^{[46]}$ Synergistic effects of Metformin and Cocoa flavanol on antioxidants were great where the mixture of them showed a fabulous impact against ROS and regulates the levels of MDA, SOD and GSH to be nearly normal.

\section{CONCLUSION}

We conclude that Metformin and cocoa have amazing anti-inflammatory and antioxidative effects against carrageen-induced inflammation especially the combination between then can give a stronger effect more than using each one alone.

\section{ACKNOWLEDGEMENT}

To those who instilled in me the value of education and the rewards and opportunities, it can generate to our parents, especially my father, who supplied me with enthusiasm, support and creative insight. His critical reading of the manuscript that helped me refine the concept of this thesis, his deep interest in the topic and unfailing encouragement are highly appreciated.

\section{CONFLICT OF INTEREST}

The author has declared no competing interests.

\section{ABBREVIATIONS}

COX: Cyclooxygenase; PGE: Prostaglandin E; TNF- $\boldsymbol{\alpha}$ : Tumor necrosis factor- $\alpha$; CRP: c-reactive protein; MDA: Malondialdehyde; SOD: Superoxide dismutase; GSH: Glutathione; Met: Metformin; Cg: Carrageenan; CF: Cocoa flavenol; ROS: Reactive oxygen species; NF-кB: Nuclear factor kappa.

\section{Ethical approval and consent to participate}

All applicable international, national and/or institutional guidelines for the care and use of animals were followed and approved by Prof Dr. Abdallah Elhoot (Head of Zoology Department- Zagazig University)

\section{Availability of data materials}

Mendeley data repository (http://dx.doi.org/10.17632/ntm476d5r8.3)

\section{Author contributions}

HA carried out the physiological, biochemical and anatomical studies, participated in the sequence alignment and drafted the manuscript.

\section{REFERENCES}

1. Nathan DM, Buse JB, Davidson MB, Ferrannini E, Holman RR, Sherwin R, et al. Medical management of hyperglycemia in type 2 diabetes: A consensus algorithm for the initiation and adjustment of therapy: a consensus statement of the American Diabetes Association and the European Association for the Study of Diabetes. Diabetes Care. 2009;32(1):193-203.

2. Stephenne X, Foretz M, Taleux N, DerZon VG, Sokal E, Hue L, et al. Metformin activates AMP-activated protein kinase in primary human hepatocytes by decreasing cellular energy status. Diabetologia. 2011;54(12):3101-3110.

3. Shaw RJ. Metformin trims fats to restore insulin sensitivity. Nature Medicine. 
2013;19(12):1570.

4. Arner $P$, Langin D. Lipolysis in lipid turnover, cancer cachexia and obesity-induced insulin resistance. Trends in Endocrinology and Metabolism. 2014;25(5):255-62.

5. Sentürk T, Günay S. The mysterious light of dark chocolate. Turkish Society of Cardiology. 2015;43(2):199-207.

6. Araujo QR, Gattward JN, Almoosawi S, Silva MDPC, Dantas PA, Júnior AQR. Cocoa and human health: from head to foot-a review. Critical Reviews in Food Science and Nutrition. 2016;56(1):1-12

7. Ludovici V, Barthelmes J, Nägele MP, Enseleit F, Ferri C, Flammer AJ, Sudano I. Cocoa, blood pressure and vascular function. Frontiers in Nutrition. 2017;4: 36

8. Chattopadhyay P, Hazarika S, Dhiman S, Upadhyay A, Pandey A, Karmakar S et al. Vitex negundo inhibits cyclooxygenase-2 inflammatory cytokine-mediated inflammation on carrageenan-induced rat hind paw edema. Pharmacognosy Research. 2012;4(3):134

9. Pecikoza UB, Tomic MA, Micov AM, Stepanovic-Petrovic RM. Metformin synergizes with conventional and adjuvant analgesic drugs to reduce inflammatory hyperalgesia in rats. Anesthesia and Analgesia. 2017;124(4):1317-29.

10. Ramos-Romero S, Ramiro-Puig E, Pérez-Cano F, Castellote C, Franch A, Castell M. Anti-inflammatory effects of cocoa in rat carrageenin-induced paw oedema. Proceedings of the Nutrition Society. 2008;67(OCE1).

11. Wang SJ, Yue W, Rahman K, Xin HL, Zhang QY, Qin LP, et al. Mechanism of treatment of kidney deficiency and osteoporosis is similar by Traditional Chinese Medicine. Current Pharmaceutical Design. 2016;22(3):312-20.

12. Guzmán-Priego CG, Méndez-Mena R, Baños-González MA, Araiza-Saldaña $\mathrm{Cl}$, Castañeda-Corral G, Torres-López JE. Antihyperalgesic effects of indomethacin ketorolac and metamizole in rats: Effects of metformin. Drug Development Research. 2017;78(2):98-104

13. Kara A, Unal D, Simsek N, Yucel A, Yucel N, Selli J. Ultra-structural changes and apoptotic activity in cerebellum of post-menopausal-diabetic rats: A histochemical and ultra-structural study. Gynecological Endocrinology. 2014;30(3):226-31.

14. Russe OQ, Möser CV, Kynast KL, King TS, Stephan H, Geisslinger G, et al Activation of the AMP-activated protein kinase reduces inflammatory nociception. The Journal of Pain. 2013;14(11):1330-40.

15. Balaji T, Ramanathan M, Menon VP. Localization of cyclooxygenase-2 in mice testis and assessment of its possible role through suppressing its expression using nimesulide: a preferential cyclooxygenase-2 inhibitor. Prostaglandins, Leukotrienes and Essential Fatty Acids. 2007;76(6):341-48.

16. Niehaus Jr W, Samuelsson B. Formation of malonaldehyde from phospholipid arachidonate during microsomal lipid peroxidation. European Journal of Biochemistry. 1968;6(1):126-30.

17. Lima P, Benassi J, Pedrosa R, Dal Magro J, Oliveira T, Filho DW. Time-course variations of DNA damage and biomarkers of oxidative stress in tilapia (Oreochromis niloticus) exposed to effluents from a swine industry. Archives of Environmental Contamination and Toxicology. 2006;50(1):23-30.

18. Hwang HJ, Lee HJ, Kim CJ, Shim I, Hahm DH. Inhibitory effect of amygdalin on lipopolysaccharide-inducible TNF-alpha and IL-1 beta mRNA expression and carrageenan-induced rat arthritis. J Microbiol Biotechnol. 2008;18(10):1641-47.

19. Umapathy E, Ndebia E, Meeme A, Adam B, Menziwa P, Nkeh-Chungag B, et al. An experimental evaluation of Albuca setosa aqueous extract on membrane stabilization, protein denaturation and white blood cell migration during acute inflammation. Journal of Medicinal Plants Research. 2010;4(9):789-95.

20. Guay J, Bateman K, Gordon R, Mancini J, Riendeau D. Carrageenan-induced paw edema in rat elicits a predominant prostaglandin E2 (PGE2) response in the central nervous system associated with the induction of microsomal PGE2 synthase-1. Journal of Biological Chemistry. 2004;279(23):24866-72.

21. Nantel F, Denis D, Gordon R, Northey A, Cirino M, Metters KM, et al. Distribution and regulation of cyclooxygenase-2 in carrageenan-induced inflammation. British Journal of Pharmacology. 1999;128(4):853-9.

22. Buadonpri $W$, Wichitnithad $W$, Rojsitthisak $P$, Towiwat $P$. Synthetic curcumin inhibits carrageenan-induced paw edema in rats. J health Res. 2009:23(1):11-6.

23. Lee S, Shin S, Kim H, Han S, Kim K, Kwon J, et al. Anti-inflammatory function of arctiin by inhibiting COX-2 expression via NF-אB pathways. Journal of Inflammation. 2011;8(1):16.

24. Chopade AR, Sayyad FJ, Naikwade NS. Pharmacological characterization of carrageenan induced heat muscle hyperalgesia in rats using non-selective, preferential and selective COX-2 inhibitors. Pharmacological Reports. 2014;66(3):353-62

25. Ogata M, Matsui T, Kita T, Shigematsu A. Carrageenan primes leukocytes to enhance lipopolysaccharide-induced tumor necrosis factor alpha production. Infection and Immunity. 1999;67(7):3284-9.

26. Vazquez E, Navarro M, SalazarY, Crespo G, Bruges G, Osorio C, et al. Systemic changes following carrageenan-induced paw inflammation in rats. Inflammation Research. 2015;64(5):333-42.

27. Murata $H$, Shimada N, Yoshioka M. Current research on acute phase proteins in veterinary diagnosis: An overview. The Veterinary Journal. 2004;168(1):28-40.

28. Bouassida ZK, Makni S, Tounsi A, Jlaiel L, Trigui M, Tounsi S. Effects of Juniperus phoenicea Hydroalcoholic Extract on Inflammatory Mediators and Oxidative Stress Markers in Carrageenan-Induced Paw Oedema in Mice. BioMed Research International. 2018.

29. Wang ZS, Liu XH, Wang M, Jiang GJ, QiuT, Chen ZY, et al. Metformin attenuated the inflammation after renal ischemia/reperfusion and suppressed apoptosis of renal tubular epithelial cell in rats. Acta Cirurgica Brasileira. 2015;30(9):617-23.

30. Liu Q, Tong D, Liu G, Gao J, Wang LA, Xu J, et al. Metformin inhibits prostate cancer progression by targeting tumor-associated inflammatory infiltration. Clinical Cancer Research. 2018;24(22):5622-34.

31. Kim SA, Choi HC. Metformin inhibits inflammatory response via AMPK-PTEN pathway in vascular smooth muscle cells. Biochemical and Biophysical Research Communications. 2012;425(4):866-72.

32. Yue W, Yang CS, DiPaola RS, Tan XL. Repurposing of metformin and aspirin by targeting AMPK-mTOR and inflammation for pancreatic cancer prevention and treatment. Cancer Prevention Research. 2014l;7(4):388-97.

33. Andújar I, Recio M, Giner R, Ríos J. Cocoa polyphenols and their potential benefits for human health. Oxidative Medicine and Cellular Longevity. 2012.

34. Martín M, Goya L, Ramos S. Preventive effects of cocoa and cocoa antioxidants in colon cancer. Diseases. 2016;4(1):6.

35. Ramos-Romero S, Pérez-Cano FJ, Pérez-Berezo T, Castellote C, Franch A, et al. Effect of a cocoa flavonoid-enriched diet on experimental autoimmune arthritis. British Journal of Nutrition. 2012;107(4):523-32.

36. Ranneh Y, Ali F, Al-Qubaisi M, Esa NM, Ismail A. The inhibitory activity of cocoa phenolic extract against pro-inflammatory mediators secretion induced by lipopolysaccharide in RAW 264.7 cells. Springer Plus. 2016;5(1):547.

37. Parsaeyan N, Mozaffari-Khosravi H, Absalan A, Mozayan MR. Beneficial effects of cocoa on lipid peroxidation and inflammatory markers in type 2 diabetic patients and investigation of probable interactions of cocoa active ingredients with prostaglandin synthase-2 (PTGS-2/COX-2) using virtual analysis. Journal of Diabetes and Metabolic Disorders. 2014;13(1):30.

38. Khedir BS, Mzid M, Bardaa S, Moalla D, Sahnoun Z, RebaiT. In vivo evaluation of the anti-inflammatory effect of pistacia lentiscus fruit oil and its effects on oxidative stress. Evidence-Based Complementary and Alternative Medicine, 2016

39. Goel A, Dani V, Dhawan D. Protective effects of zinc on lipid peroxidation, antioxidant enzymes and hepatic histoarchitecture in chlorpyrifos-induced toxicity. Chemico-Biological Interactions. 2005;156(2-3):131-40

40. Nardi G, Junior JS, Delle Monache F, Pizzolatti M, Ckless K, Ribeiro-do-Valle, R Antioxidant and anti-inflammatory effects of products from Croton celtidifolius Bailon on carrageenan-induced pleurisy in rats. Phytomedicine. 2007;14(2-3):115-22.

41. Marycz K, Tomaszewski KA, Kornicka K, Henry BM, Wronski S, Tarasiuk J et al. Metformin decreases reactive oxygen species, enhances osteogenic properties of adipose-derived multipotent mesenchymal stem cells in vitro and increases bone density in vivo. Oxidative Medicine and Cellular Longevity. 2016.

42. Ahangarpour A, Zeidooni L, Rezaei M, Alboghobeish S, Samimi A, Oroojan AA Protective effect of metformin on toxicity of butyric acid and arsenic in isolated liver mitochondria and langerhans islets in male mice: an in vitro study. Iranian Journal of Basic Medical Sciences. 2017;20(12):1297.

43. Cho JG, Song JJ, Choi J, Im GJ, Jung HH, Chae SW. The suppressive effects of metformin on inflammatory response of otitis media model in human middle ear epithelial cells. International Journal of Pediatric Otorhinolaryngology. 2016;89:28-32.

44. Shin HS, Ko J, Kim DA, Ryu ES, Ryu HM, Park SH, et al. Metformin ameliorates the phenotype transition of peritoneal mesothelial cells and peritoneal fibrosis via a modulation of oxidative stress. Scientific Reports. 2017;7(1):5690.

45. Garabadu D, Krishnamurthy S. Metformin attenuates hepatic insulin resistance in type-2 diabetic rats through PI3K/Akt/GLUT-4 signalling independent to bicuculline-sensitive GABAA receptor stimulation. Pharmaceutical Biology. 2017;55(1):722-28.

46. Decroix L, Soares DD, Meeusen R, Heyman E, Tonoli C. Cocoa flavanol supplementation and exercise: A systematic review. Sports Medicine. 2018;48(4):867-92

47. Taub PR, Ramirez-Sanchez I, Patel M, Higginbotham E, Moreno-Ulloa A Román-Pintos LM. et al. Beneficial effects of dark chocolate on exercise capacity in sedentary subjects: underlying mechanisms. A double blind, randomized, placebo controlled trial. Food and Function. 2016;7(9):3686-93.

48. Steffen Y, Gruber C, Schewe T, Sies H. Mono-O-methylated flavanols and other flavonoids as inhibitors of endothelial NADPH oxidase. Archives of Biochemistry and Biophysics. 2008;469(2):209-19

49. Ruijters EJ, Haenen GR, Weseler AR, Bast A. The cocoa flavanol (-)-epicatechin protects the cortisol response. Pharmacological Research. 2014;79:28-33. 